\title{
A Short-Term Decision Model for Electricity Retailers: Electricity Procurement and Time-of-Use Pricing
}

\author{
Feihu Hu, Xuan Feng and Hui Cao *(D) \\ School of Electrical Engineering, Xi'an Jiaotong University, Xi'an 710049, China; \\ hufeihu@mail.xjtu.edu.cn (F.H.); fengxuan1990@163.com (X.F.) \\ * Correspondence: huicao@mail.xjtu.edu.cn; Tel.: +86-139-9119-3207
}

Received: 3 November 2018; Accepted: 20 November 2018; Published: 22 November 2018

\begin{abstract}
This paper establishes a short-term decision model, based on robust optimization, for an electricity retailer to determine the electricity procurement and electricity retail prices. The electricity procurement process includes purchasing electricity from generation companies and from the spot market. The selling prices of electricity for the customers are based on time-of-use (TOU) pricing which is widely employed in modern electricity market as a demand response program. The objective of the model is to maximize the expected profit of the retailer through optimizing the electricity procurement strategy and electricity pricing scheme. A price elasticity matrix (PEM) is adopted to model the demand response. Also, uncertainty in spot prices is modeled using a robust optimization approach, in which price bounds are considered instead of predicted values. Using a robust optimization approach, the retailer can adjust the level of robustness of its decisions through a robust control parameter. A case study is presented to illustrate the performance of the model. The simulation results demonstrate that the developed model is effective in increasing the expected profit of the retailer and flattening the load profiles of customers.
\end{abstract}

Keywords: robust optimization; demand response; electricity procurement; spot market; time-of-use (TOU) pricing

\section{Introduction}

In emerging electricity markets, electricity retailers generally purchase electricity from generation companies and the spot market, and resell energy to customers [1-3]. Compared with trading on the spot market, it is more profitable for retailers to purchase electricity from generation companies [4]. Therefore, an electricity retailer typically procures the major portion of the electricity demanded by its customers directly from generation companies, and purchases the remaining portion of the electricity from the spot market at the spot price [5]. The profit of an electricity retailer derives from the difference between the revenue from selling electricity and the cost of purchasing energy. Consequently, an electricity retailer faces the problem of maximizing its profit through determining the optimal electricity procurement strategy and electricity retail prices.

There are some studies focusing on the aforementioned problem faced by an electricity retailer. The amount of electricity to be purchased and the purchase price should be predetermined in any bilateral contract [6,7]. A risk-constrained stochastic programming method is presented in [8] to address the problem of procuring electric energy faced by a retailer. The proposed decision-making framework allows the retailer to determine the optimal selling prices and the quantities of energy purchased from the market and contracts. A similar problem is solved in [9] with a bilevel stochastic programming approach. Besides, the stochastic programming model is presented in $[10,11]$ to solve the problem of determining the optimal bilateral contracts and electricity prices for end-users. Also, a mixed-integer stochastic programming framework is proposed in [12] for deciding the sale price of the 
retailer and optimizing the electricity procurement. Reference [13] develops a multistage stochastic optimization approach to resolve the problem of satisfying instantaneous and variable loads faced by a retailer, which effectively optimizes an electricity contract portfolio of spot and forward contracts. In [14], an analogous model is proposed in which both electricity selling price and electricity contract are optimized in order to maximize the profit and minimize the risks simultaneously. Recently in [15], a multiobjective framework is proposed to maximize the profit of a retailer and minimize the electricity retail prices simultaneously.

Demand response (DR) is defined as the electricity consumption change in response to price signals (e.g., time-varying electricity prices) or incentive payments [16]. DR program is a program or pricing scheme established to motivate end-users to reschedule their energy consumption in response to changes in the electricity prices, or to give appropriate incentive payments to customers to adjust their load profiles $[17,18]$. An efficient DR program can reduce the peak load, compensate for uncertainties of renewable energy generation, and increase the profits [19-21]. Also, a well designed DR program can help retailers to reduce the cost of purchasing electricity [22,23]. Recently, time-of-use (TOU) pricing has attracted growing attention both in academia and industry since it can reduce the inefficiency of single pricing and increase economic efficiency in terms of electricity production and consumption $[24,25]$. Furthermore, TOU pricing schemes are more widely used than other dynamic pricing schemes, because they are easier and less costly to implement [26]. Evaluation of TOU pricing benefits has been extensively discussed in $[27,28]$. Similarly, the advantages of the implementation of TOU pricing in electricity markets are analyzed in [29].

Although previous studies have provided related studies for electricity procurement and electricity retail price optimization problem of a retailer, most of the existing literature uses stochastic programming to model the uncertainties [30]. The stochastic-based methods for tackling uncertainty in existing researches require historical data or the probability density functions of uncertain parameters, which is not always known by the decision maker [31,32]. Besides, it is usually difficult to precisely forecast spot prices or estimate the probability distribution of the forecast error [33]. Recently, robust optimization, which was first proposed in [34], has been widely adopted for decision making under uncertain environment. It's an efficient modeling technique for stochastic optimization problems, especially when the information on the nature of uncertainty is not acquired by the decision maker [35].

This paper establishes a short-term decision model based on robust optimization for an electricity retailer: (1) to determine the optimal electricity procurement strategy from multiple generation companies and spot market, and (2) to determine the electricity selling prices for customers based on TOU pricing. In this model, the retailer purchases the major portion of demanded electricity from generation companies, and purchases a small amount of electricity from spot market as supplementary. Considering the differences in procurement cost from generation companies and regulatory restrictions imposed by supervision department, the retailer should decide the optimal purchase allocation among different generation companies. Furthermore, the uncertainty in spot prices is addressed in the model via robust optimization approach. When selling electricity, the retailer sets the electricity retail prices, and the customers respond to the prices by adjusting their electricity usage. Price elasticity matrix (PEM) which describes the relative change in electricity consumption resulting from the change in electricity price is generally used to capture the DR to TOU pricing [36-39]. The elastic behavior of customers in response to different TOU prices is modeled via PEM.

The remaining parts of the paper are organized as follows: Section 2 briefly describes the theoretical basis of the established model. A mathematical representation of the model is presented in Section 3. Section 4 provides the simulation results from a case study. Finally, conclusions are presented in Section 5. 


\section{Theoretical Basis}

\subsection{Decision Framework}

This paper considers an electricity retailer participating in the electricity market through purchasing electricity from generation companies and the spot market and reselling electricity to customers. A short-term decision model is established for the retailer, where the short-term decision specifically means that the decisions are made on a day-ahead basis. The short-term decisions, which include the amount and corresponding trading hours of the purchased electricity as well as the retail prices, are made by the retailer one day before the planning horizon. These decisions are made under uncertainty in spot prices and kept constant throughout the planning horizon.

Since we address the short-term decision making problem for a retailer, the planning horizon considered here refers to one day and the decisions are made at hourly level during the planning horizon. In a real electricity market, electricity customers are generally divided into several types according to different electricity usage patterns. The customer categorization can help the retailer to design precise pricing strategy such that the energy efficiency is improved [40]. Therefore, in this paper, the electricity demand of customers is elastic and different customers have different price elasticity characteristics.

\subsection{Uncertainty Modeling of Spot Price}

An electricity retailer faces many uncertainties when participating in electricity market. The next-day spot price is the major source of uncertainty considered in this paper. The uncertain nature of spot prices implies that the spot market cost, which refers to the cost of purchasing electricity from spot market, cannot be accurately determined by the retailer [41]. In this paper, the robust optimization approach proposed in [42] is used to build a robust optimization model for the short-term decision making problem of the retailer. In this approach, the lower and upper limits of spot prices are used instead of predicted values or possible price scenarios. With the robust optimization model, the retailer can control the extent of uncertainty in spot prices through a robust control parameter, so as to achieve a tradeoff between economic benefits and robustness.

\subsection{TOU Pricing}

A TOU pricing scheme sets different unit electricity selling prices for electricity consumption during different time periods in a day [43]. Generally, in a TOU pricing, a day is divided into several time periods and the electricity retail price is different in different time periods [20]. The objective of applying TOU pricing is to influence customer behavior through price signals, such that the profit of the retailer is maximized and the load throughout the day is flattened. In this paper, for a specific type of customer, a day is divided into $N$ time periods, and $T_{j, h}$ refers to the hours included in time period $h$ for customer $j(h=1, \ldots, N) . p_{j, h}$ is the electricity retail price for customer $j$ in time period $h$. Obviously, the performance of TOU pricing will increase with more precise period dividing. It is worth noting that the number of time periods $N$ depends on not only the electricity usage patterns of customers, but also the desired load adjustment of retailer.

After determining the optimal TOU pricing scheme, the retailer will inform its customers of the selling prices one day in advance. Having got the information of electricity prices, the customers can benefit through responding to TOU prices. They may reduce their electricity consumption when retail prices are high and consume more electricity when retail prices are relatively lower.

\subsection{Demand Response}

The customer demand response to electricity selling prices is modeled using a PEM. The element of the PEM, which is called as price elasticity coefficient, is defined as:

$$
\left.\varepsilon_{j, m, n}=\left[\left(q_{j, m}-q_{j, m}^{0}\right) / q_{j, m}^{0}\right)\right] /\left[\left(p_{j, n}-p_{j, n}^{0}\right) / p_{j, n}^{0}\right]=\Delta q_{j, m} / \Delta p_{j, n}
$$


where $\varepsilon_{j, m, n}$ is the price elasticity coefficient of customer $j$, which reflects the relative variation of electricity consumption in hour $m$ with respect to the relative change in retail price of hour $n$. Here, $p_{j, n}^{0}$ is the reference price and $q_{j, m}^{0}$ corresponds to the electricity consumed in hour $m$ when the reference price is applied. Therefore, $q_{j, m}-q_{j, m}^{0}$ and $p_{j, n}-p_{j, n}^{0}$ are the absolute change in electricity consumption and retail price, respectively. Analogously, $\Delta q_{j, m}$ and $\Delta p_{j, n}$ are the relative variation in electricity consumption and retail price, respectively. It is worth mentioning that when $m=n, \varepsilon_{j, m, n}$ is called as self-elasticity, whereas when $m \neq n, \varepsilon_{j, m, n}$ refers to cross-elasticity. Considering (1), the total relative variation in electricity consumption after using a PEM can be expressed as:

$$
\Delta q_{j, m}=\sum_{n \in T} \varepsilon_{j, m, n} \cdot \Delta p_{j, n}, \forall m \in T, \varepsilon_{j, m, n} \in E_{j}
$$

Given (2), the amount of electricity consumed in hour $m$ when applying TOU prices is shown as:

$$
q_{j, m}=\left(1+\sum_{n \in T} \varepsilon_{j, m, n} \Delta p_{j, n}\right) \cdot q^{0} j, m, \forall m \in T, \varepsilon_{j, m, n} \in E_{j}
$$

\section{Developed Mathematical Model}

Mathematical model of the robust optimization-based short-term decision making problem is established in this section.

\subsection{Assumptions}

Several assumptions are considered as follows:

- The electricity retailer considered in this paper is a price-taker retailer since it only buys a small amount of electricity from the spot market, which means that its purchasing behavior in the spot market does not affect the spot prices.

- Transmission costs and constraints such as lines capacity constraints, voltage limits and reserve constraints are not included in the model. Since a price-taker retailer cares about market mechanisms and pricing schemes but not the transmission and distribution network structure.

- It is assumed that the reference load profiles and price elasticity coefficients for each type of customer have been estimated based on historical data and customer surveys.

\subsection{Objective Function}

The profit of the retailer equals to the expected revenue from electricity sales minus the total purchase cost. A retailer can purchase power from generation companies and spot market, such that the total purchase cost consists of the procurement cost from generation companies and the spot market cost. The components of the objective function are described in detail as follows.

\subsubsection{Expected Revenue}

The expected revenue acquired from selling electricity to customers during the planning horizon is calculated as:

$$
E R=\sum_{j \in C} \sum_{h \in H} \sum_{t \in T_{j, h}} p_{j, h} \cdot q_{j, t}
$$

where $p_{j, h}$ is the electricity retail price offered to customer $j$ during time period $h$, and $q_{j, t}$ refers to the amount of electricity consumed by customer $j$ at the price of $p_{j, h}$ in hour $t$. 


\subsubsection{Procurement Cost from Generation Companies}

The procurement cost, which reflects the cost of purchasing electricity from generation companies, is expressed as a quadratic function, as shown in (5):

$$
P C=\sum_{i \in G} \sum_{t \in T} a_{i} \cdot P^{2}{ }_{i, t}+b_{i} \cdot P_{i, t}+c_{i}
$$

where $a_{i}, b_{i}$, and $c_{i}$ are the procurement cost coefficients of generation company $i$. Note that the profit of selling electricity of generation companies has been implied in the function.

\subsubsection{Spot Market Cost}

The electricity retailer purchases a small portion of electricity from spot market. Hence, the spot market cost, which refers to the cost of spot market procurement, is calculated by:

$$
S C=\sum_{t \in T} \lambda_{t} \cdot P_{t}^{S}
$$

where $\lambda_{t}$ is the spot price in hour $t$, and $P_{t}^{s}$ corresponds to the quantity of electricity purchased from the spot market in hour $t$.

As mentioned before, the spot price $\lambda_{t}$ is difficult to forecast due to its volatility, but one can still determine a reasonable range for $\lambda_{t}$ according to statistical data. Here, each $\lambda_{t}$ is an independent, symmetric and bounded stochastic coefficient which takes values in $\left[\bar{\lambda}_{t}-\delta_{t}, \bar{\lambda}_{t}+\delta_{t}\right]$ with $\delta_{t} \geq 0$, where $\delta_{t}$ is the maximum possible deviation from the nominal spot price $\bar{\lambda}_{t}$ [44].

As a commercial company, the electricity retailer pursues profit maximization. Therefore, maximizing the expected profit of the retailer is the objective function of the model. The mathematical formulation of the objective function is expressed as follows:

$$
\text { Maximize } E P=\sum_{j \in C} \sum_{h \in H} \sum_{t \in T_{j, h}} p_{j, h} \cdot q_{j, t}-\sum_{i \in G} \sum_{t \in T}\left(a_{i} \cdot P^{2}{ }_{i, t}+b_{i} \cdot P_{i, t}+c_{i}\right)-\sum_{t \in T} \lambda_{t} \cdot P_{t}^{s}
$$

\subsection{Constraints}

The retailer faces the following technical constraints and regulatory restrictions in the short-term decision making process.

\subsubsection{Power Generation Limits}

The power generation limits of generation companies are expressed as follows:

$$
P_{i}^{\min } \leq P_{i, t} \leq P_{i}^{\max }, \forall i \in G, \forall t \in T
$$

where $P_{i}^{\min }$ and $P_{i}^{\max }$ are the minimum power output and maximum power output of generation company $i$, respectively.

\subsubsection{Ramp-Up/Down Constraints}

The variation of output power is limited in transition from hour $t-1$ to hour $t$. This limitation is called ramp rate limit, which is expressed as follows:

$$
\begin{aligned}
& P_{i, t}-P_{i, t-1} \leq R U_{i}, \forall i \in G, \forall t \in T \\
& P_{i, t-1}-P_{i, t} \leq R D_{i}, \forall i \in G, \forall t \in T
\end{aligned}
$$

where $R U_{i}$ and $R D_{i}$ are the ramp-up/down limits of generation company $i$. 


\subsubsection{Constraints on Retail Prices}

Since retailers have a natural monopoly in electricity retail markets, retail prices should be within a certain range to protect the interests of electricity consumers. The constraint on retail prices are expressed as follows:

$$
p_{j}^{\min } \leq p_{j, h} \leq p_{j}^{\max }, \forall j \in C, \forall h \in H
$$

where $p_{j}{ }^{\min }$ and $p_{j}{ }^{\max }$ are minimum/maximum limits of retail price for customers $j$. Keeping in mind that the value of $p_{j}{ }^{\min }$ and $p_{j}{ }^{\max }$ should be set appropriately to ensure price fairness and avoid vicious competition.

\subsubsection{Constraints on Power Balance}

The power balance constraint should be satisfied as follows:

$$
\sum_{i \in G} P_{i, t}+P_{t}^{s}=\sum_{j \in C} q_{j, t}, \forall t \in T
$$

where $q_{j, t}$ is the electricity consumption of customer $j$ in hour $t, p_{i, t}$ refers to the quantity of electricity bought from generation company $i$ in hour $t$, and $P_{t}^{s}$ is the amount of electricity purchased from spot market in hour $t$.

\subsection{Robust Optimization Approach}

In the objective function (7), for each feasible $p_{j, h}$ and corresponding $q_{j, t}$ in the solution domain, the spot market cost must be minimized, as well as the procurement cost. Therefore, Minimize $\sum_{t \in T} \lambda_{t} \cdot P_{t}^{s}$ forms the following standard mixed-integer programming (MIP) problem:

$$
\underset{x_{j}, \forall_{j}}{\operatorname{Minimize}} \sum_{j=1}^{n} e_{j} \cdot x_{j}
$$

Subject to:

$$
\begin{gathered}
\sum_{j=1}^{n} a_{i j} \cdot x_{j} \leq b_{i}, \quad i=1, \ldots, m \\
x_{j} \geq 0, \quad j=1, \ldots, n \\
x_{j} \in\{0,1\} \quad \text { for some } j=1, \ldots, n
\end{gathered}
$$

In (13), the coefficients $e_{j}$ of the objective function are considered to be known. If these coefficients are random variables within known bounds, the above MIP problem can be recast as a robust mixed-integer programming (RMIP) problem. In typical applications, we have estimates for the coefficients $e_{j}$ and an estimate of its range $d_{j}$ in spite of the lack of exact distribution of these coefficients [42]. Therefore, it is reasonable to assume that every coefficient takes values in the interval $\left[\bar{e}_{j}-d_{j}, \bar{e}_{j}+d_{j}\right]$, where $d_{j}$ is the maximum possible deviation from the nominal coefficient $\bar{e}_{j}[31,35,44]$. Additionally, to formulate the robust counterpart, an integer robust control parameter $\Gamma_{0}$ is defined to control the level of robustness in the objective function, which takes values in the interval $\left[0,\left|J_{0}\right|\right]$, where $J_{0}=\left\{j \mid d_{j}>0\right\}$. When $\Gamma_{0}=0$, it implies that the uncertainty of the coefficients is completely ignored, whereas when $\Gamma_{0}=\left|J_{0}\right|$, all cost deviations of objective function are considered, leading to the most conservative solution [45].

The proposed robust counterpart of optimization problem (13)-(16) is as follows:

$$
\underset{x_{j}, \forall j}{\operatorname{Minimize}} \sum_{j=1}^{n} \bar{e}_{j} \cdot x_{j}+\underset{\left\{S_{0}\left|S_{0} \subseteq J_{0},\right| S_{0} \mid \leq \Gamma_{0}\right\}}{\operatorname{Maximize}}\left\{\sum_{j \in S_{0}} d_{j} \cdot\left|x_{j}\right|\right\}
$$




$$
\text { Subject to (14)-(16) }
$$

By Theorem 1 in [42], the above RMIP problem can be rewritten in the following form:

$$
\underset{x_{j}, \xi_{j}, y_{j}, \forall j ; \beta}{\operatorname{Minimize}} \sum_{j=1}^{n} \bar{e}_{j} \cdot x_{j}+\beta \cdot \Gamma_{0}+\sum_{j=1}^{n} \xi_{j}
$$

Subject to:

$$
\begin{gathered}
\text { Constraints (14)-(16) } \\
\beta+\xi_{j} \geq d_{j} \cdot y_{j}, \quad j \in J_{0} \\
\beta \geq 0 \\
\xi_{j} \geq 0, \quad j=1, \ldots, n \\
y_{j} \geq 0, \quad j=1, \ldots, n \\
x_{j} \leq y_{j}, \quad j=1, \ldots, n
\end{gathered}
$$

The objective function (19) and corresponding constraints (20)-(25) are obtained based on duality theory. A detailed description of how to convert the objective function (17) into (19) is given in [42,44]. Variables $\beta$ and $\xi_{j}$ are the dual variables of optimization problem (13)-(16) while $y_{j}$ is an auxiliary variable used to obtain the equivalent linear expression.

Based on the proposed robust optimization approach, the short-term decision model for the retailer can be reformulated as a robust mixed-integer nonlinear programming problem. The robust model of the retailer's decision making problem is presented in Equations (26)-(32).

$$
\text { Maximize } \sum_{j \in C} \sum_{h \in H} \sum_{t \in T_{j, h}} p_{j, h} \cdot q_{j, t}-\sum_{i \in G} \sum_{t \in T}\left(a_{i} \cdot P^{2}{ }_{i, t}+b_{i} \cdot P_{i, t}+c_{i}\right)-\sum_{t=1}^{24} \bar{\lambda}_{t} \cdot P_{t}^{s}-\beta \cdot \Gamma_{0}-\sum_{t=1}^{24} \xi_{t}
$$

Subject to:

$$
\begin{gathered}
\text { Constraints (8)-(12) } \\
\beta+\xi_{t} \geq \delta_{t} \cdot y_{t}, \quad t=1, \ldots, 24 \\
\beta \geq 0 \\
\xi_{t} \geq 0, \quad t=1, \ldots, 24 \\
y_{t} \geq 0, \quad t=1, \ldots, 24 \\
P_{t}{ }^{s} \leq y_{t}, \quad t=1, \ldots, 24
\end{gathered}
$$

It should be noted that $p_{j, h}, P_{i, t}$, and $P_{t}^{s}$ are the independent variables in the model. The robust decision making model (26)-(32) is formulated in a mixed-integer nonlinear programming format that can be solved via evolutionary algorithms.

\section{Case Study}

\subsection{Data}

In this section, a case study is presented to demonstrate the application of the proposed model. In this case study, we consider an electricity retailer who purchases electricity from three generation companies and the spot market, and resells electric energy to three types of customers. Table 1 provides the parameters of generation companies. We will use G1, G2, and G3 to represent these three generation companies. 
Table 1. Parameters of generation companies.

\begin{tabular}{|c|c|c|c|c|c|c|c|}
\hline$i$ & $a_{i}\left(\$ / \mathbf{M W}^{2} \mathbf{h}\right)$ & $b_{i}(\$ / M W h)$ & $c_{i}(\$ / \mathrm{h})$ & $P_{i} \min (\mathbf{M W})$ & $P_{i} \max (\mathbf{M W})$ & $R U_{i}(\mathrm{MW} / \mathrm{h})$ & $R D_{i}(\mathrm{MW} / \mathrm{h})$ \\
\hline 1 & 0.00052 & 25.92 & 1149.84 & 150 & 470 & 80 & 80 \\
\hline 2 & 0.00076 & 25.26 & 1576.32 & 135 & 460 & 80 & 80 \\
\hline 3 & 0.00095 & 25.94 & 576.35 & 73 & 243 & 50 & 50 \\
\hline
\end{tabular}

The electricity customers are categorized into three types, i.e., commercial customers, residential customers, and industrial customers. The reference load profiles of customers, which are modified on the basis of load profiles from [24], are shown in Figure 1.

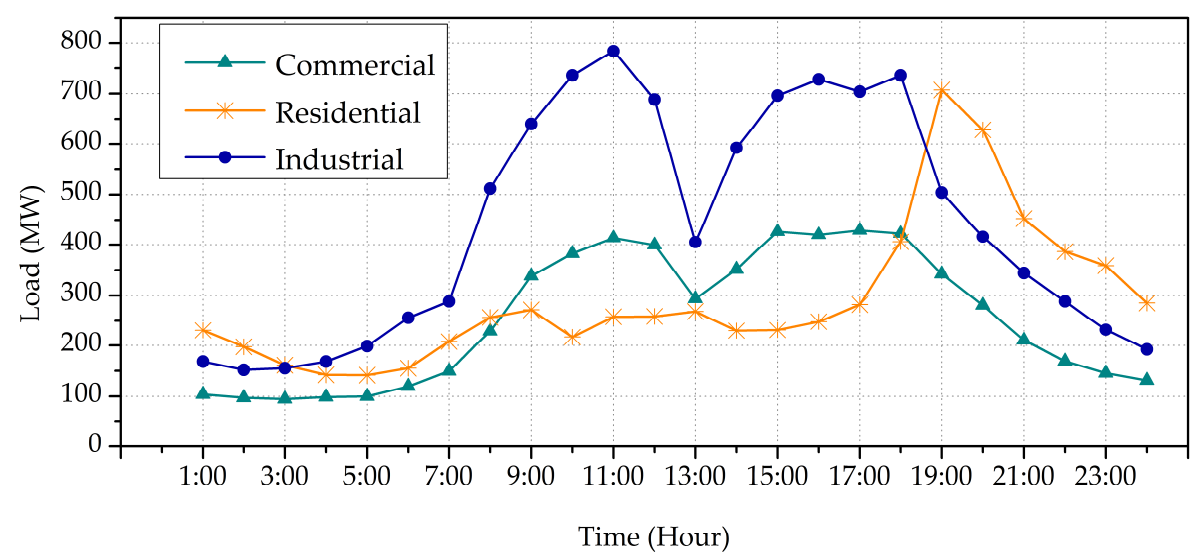

Figure 1. Reference load profiles.

The lower, upper and nominal values of spot prices are depicted in Figure 2.

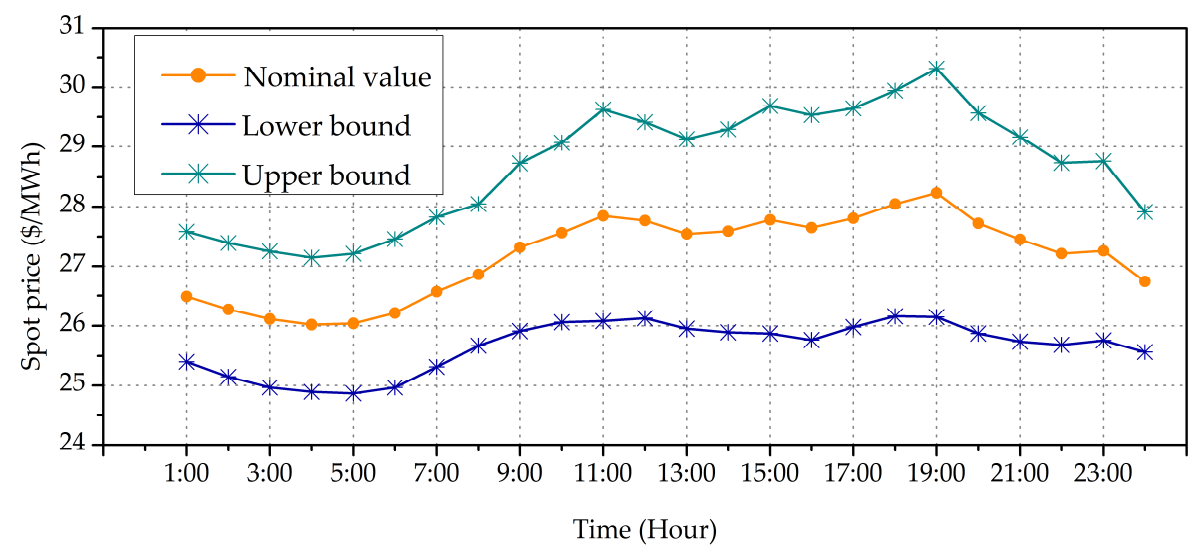

Figure 2. Lower, upper and nominal values of spot prices.

\subsection{Results}

Using the input data presented above, we propose three simulation cases to investigate the performance of the established model:

Case 1: This case simulates the situation without a TOU pricing scheme. In this case, we assume that all consumers would be charged the reference price of $40 \$ / \mathrm{MWh}$. Since the retail price remains constant during the planning horizon, customers have no incentive to reschedule their electricity consumption. This case can be regarded as a benchmark for the following comparisons.

Case 2: In this case, a TOU pricing scheme with three time periods is employed to influence customer behavior. The lower and upper limits of retail prices are set as 20\$/MWh and 70\$/MWh, respectively. For each type of customer, a day is divided into three time periods (on-peak, mid-peak, 
off-peak) according to its reference load profile, and each time period consists of several hours. The time period partition is illustrated in Table 2.

Table 2. Time period partition.

\begin{tabular}{cccc}
\hline Customer & On-Peak & Mid-Peak & Off-Peak \\
\hline Commercial & $10: 00-12: 00,15: 00-18: 00$ & $8: 00-9: 00,13: 00-14: 00,19: 00-23: 00$ & $24: 00-7: 00$ \\
Residential & $18: 00-22: 00$ & $7: 00-17: 00,23: 00-1: 00$ & $2: 00-6: 00$ \\
Industrial & $9: 00-12: 00,15: 00-18: 00$ & $7: 00-8: 00,13: 00-14: 00,19: 00-22: 00$ & $23: 00-6: 00$ \\
\hline
\end{tabular}

The variation of customer load in response to TOU prices is calculated using PEM matrices. Considering the differences in electricity consumption habits and price sensitivities among different types of customers, we propose three PEM matrices based on [22,25]. The price elasticity coefficients are shown in Table 3.

Table 3. Price elasticity coefficients of customers.

\begin{tabular}{ccccc}
\hline Customer & $\boldsymbol{\varepsilon}_{\boldsymbol{j}, \boldsymbol{m}, \boldsymbol{n}}$ & On-Peak & Mid-Peak & Off-Peak \\
\hline \multirow{3}{*}{ Commercial } & On-peak & -0.38 & 0.015 & 0.021 \\
& Mid-peak & 0.02 & -0.137 & 0.018 \\
& Off-peak & 0.008 & 0.01 & -0.16 \\
\hline \multirow{3}{*}{ Residential } & On-peak & -0.65 & 0.011 & 0.014 \\
& Mid-peak & 0.01 & -0.102 & 0.012 \\
& Off-peak & 0.004 & 0.007 & -0.123 \\
\hline \multirow{2}{*}{ Industrial } & On-peak & -0.34 & 0.009 & 0.013 \\
& Mid-peak & 0.002 & -0.241 & 0.003 \\
& Off-peak & 0.007 & 0.011 & -0.105 \\
\hline
\end{tabular}

Case 3: Compared with Case 2, a day is divided into 24 time periods in this case and the TOU prices are optimized for each time period. Actually, the TOU pricing scheme with 24 time periods can be regarded as a special case of TOU pricing in which each time period corresponds to an hour. The effectiveness of these two kinds of TOU pricing schemes will be discussed in the following.

The three cases are solved using a genetic algorithm in the Visual Studio environment. The solution in case $\Gamma_{0}=10$ is presented below to illustrate the performance of the robust model. The electricity retail prices for customers are illustrated in Figure 3. In Case 1, the electricity selling price is $40 \$$ /MWh and the price remains stable throughout the day. In the second case, it is obvious to see that the electricity retail prices are higher than the reference price during on-peak time periods and lower than 40\$/MWh in off-peak time periods. In mid-peak time periods, the TOU prices are slightly reduced when compared with the reference price. Compared with Case 2, the electricity retail prices are further optimized in Case 3 such that the optimal hourly prices are achieved. In addition to the overall trend, we can also observe difference in price fluctuations among different types of customers. The maximum price fluctuation corresponds to residential customers, especially in on-peak hours. On the contrary, the industrial customers are more sensitive to price because of their massive consumption of electricity. 


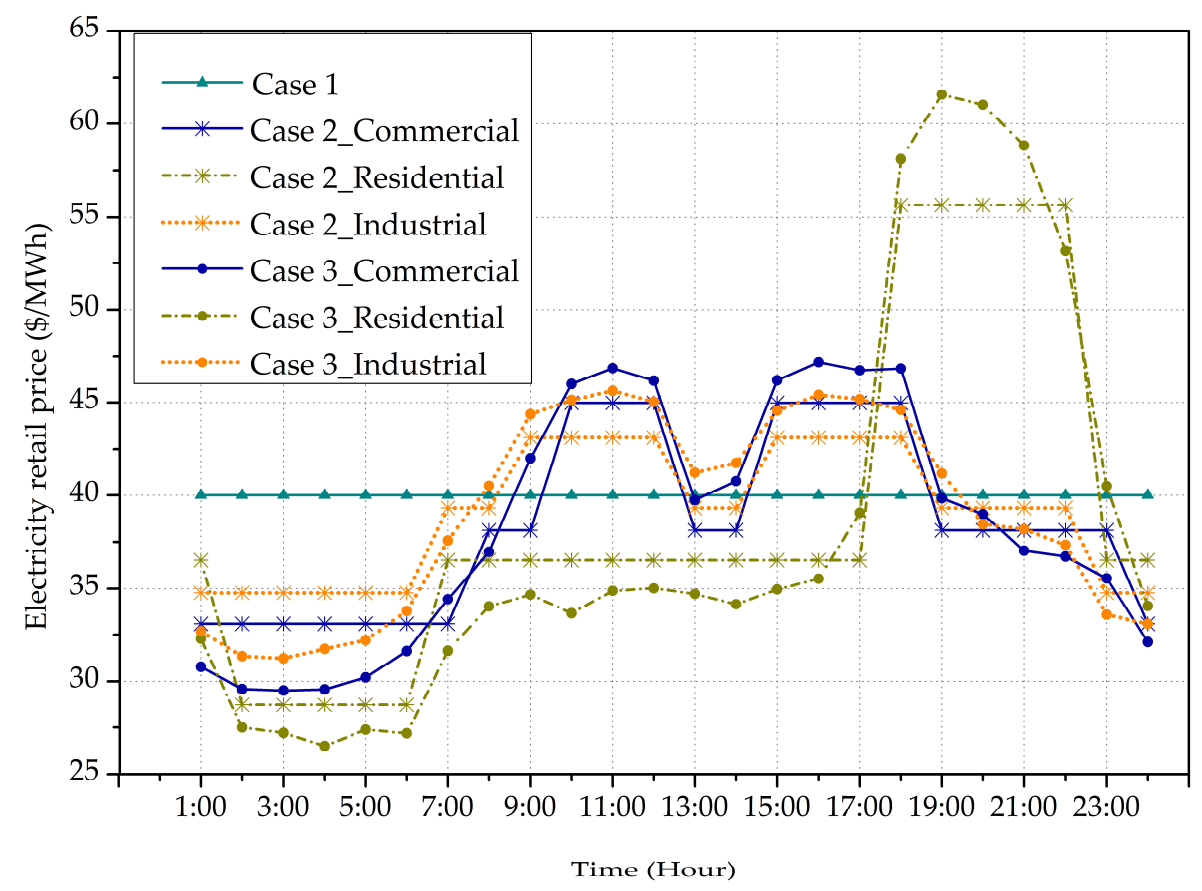

Figure 3. Electricity retail prices for customers.

Figure 4 compares the load profile of each type of customer for the three cases. In Case 2, the residential customers greatly reduce their electricity consumption during on-peak time period due to the quite high retail prices. The on-peak load of industrial customers is also significantly reduced such that they can reduce electricity bills. This can be implemented by rescheduling the production plan or shifting high energy consumption processes to off-peak hours. Compared with the reference load profile, the commercial customers do not obviously change their electricity usage during on-peak hours because load curtailment may influence their income in business hours. Besides, the electricity consumption of all types of customers is significantly increased in off-peak time periods and slightly increased during mid-peak hours. In the third case, the load profiles of customers are further adjusted via employing a more precise TOU pricing scheme, which demonstrates the advantage of TOU pricing with more time periods. The comparison analysis indicates that the TOU pricing designed by the short-term decision model can effectively flatten the load profile.

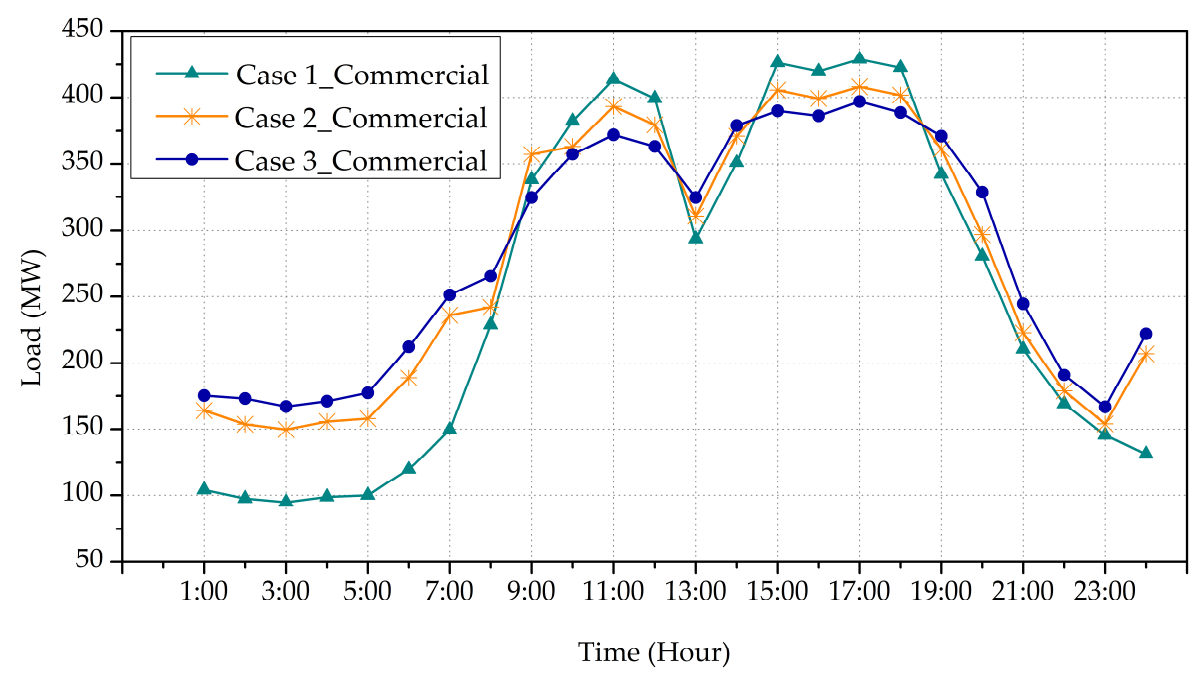

(a)

Figure 4. Cont. 


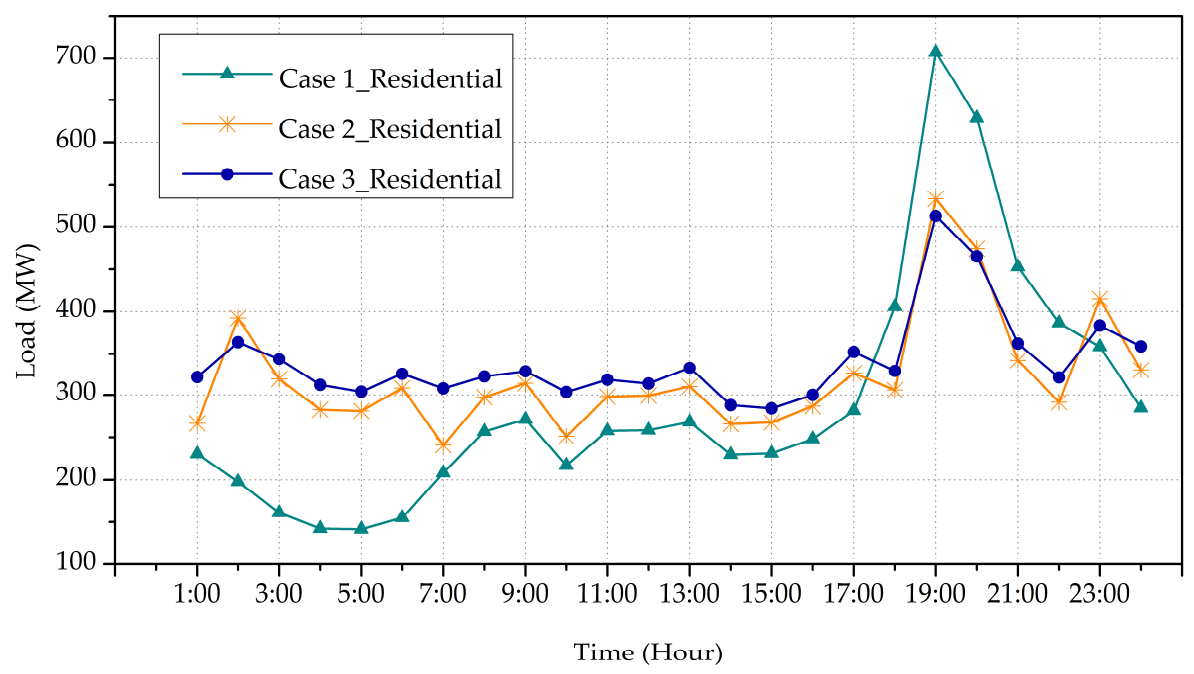

(b)

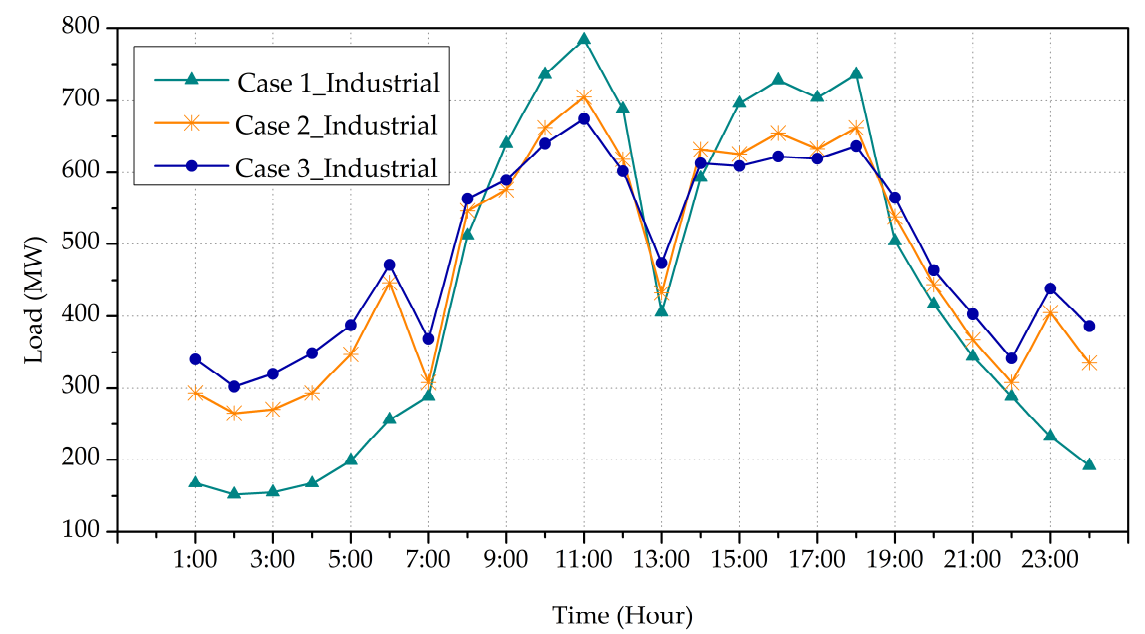

(c)

Figure 4. (a) Load profiles of commercial customers; (b) Load profiles of residential customers; (c) Load profiles of industrial customers.

As illustrated in Figure 5, the total load profile in Case 2 is smoother than that in Case 1, and the total load profile is further flattened in Case 3. This implies that the retailer can encourage its customers to change their electricity consumption habits.

We also compare the total daily load in Table 4 . From Table 4 we observe an obvious increase in electricity consumption of customers when TOU pricing scheme is applied, especially in Case 3. Compared with Case 1, the overall electricity consumption of customers is increased by $8.49 \%$ in Case 2 and increased by $12.73 \%$ in Case 3 . This reflects the fact that the TOU prices activate their potentials to consume more electricity.

The purchased power from generation companies is shown in Figure 6. Obviously, when using TOU pricing, the purchased power from all three generation companies are significantly increased during night time. This is mainly because the total load after applying TOU pricing is flattened such that the off-peak load in the night is much increased. 


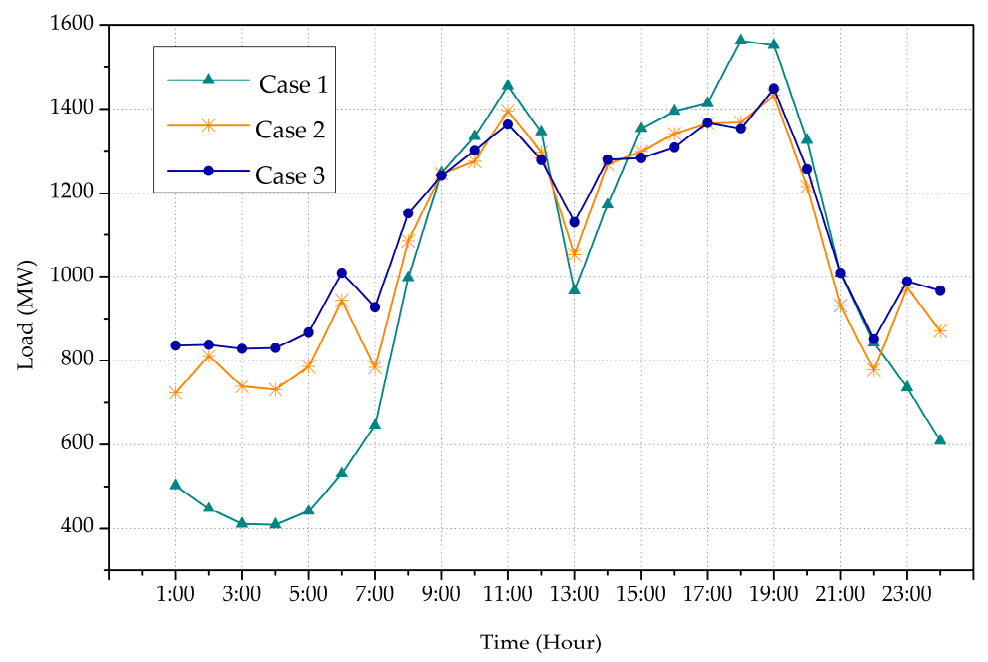

Figure 5. Comparison of total load.

Table 4. Total daily load.

\begin{tabular}{ccccc}
\hline Case & Commercial (MWh) & Residential (MWh) & Industrial (MWh) & Overall (MWh) \\
\hline Case 1 & 6147.53 & 6979.23 & 10583.06 & 23709.82 \\
Case 2 & 6658.52 & 7698.34 & 11366.65 & 25723.51 \\
Case 3 & 6798.75 & 8152.30 & 11776.31 & 26727.36 \\
\hline
\end{tabular}

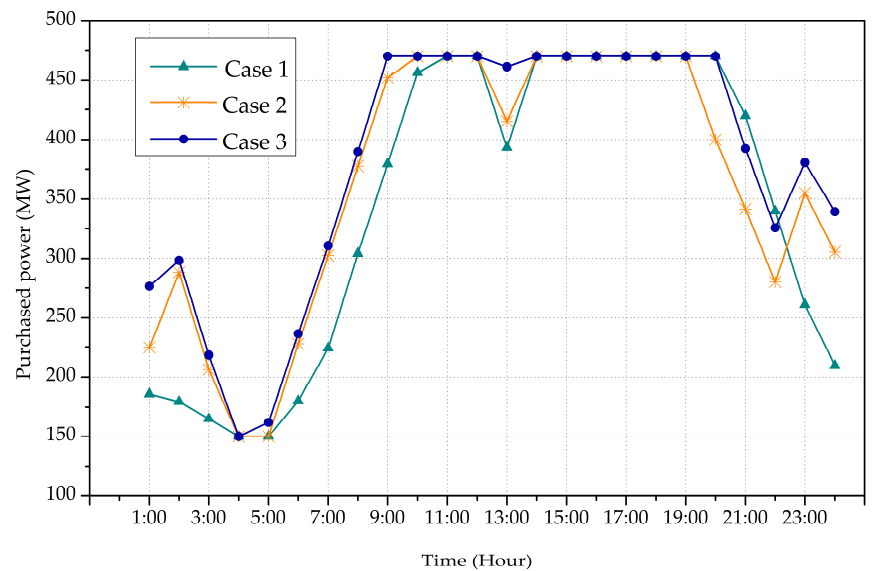

(a)

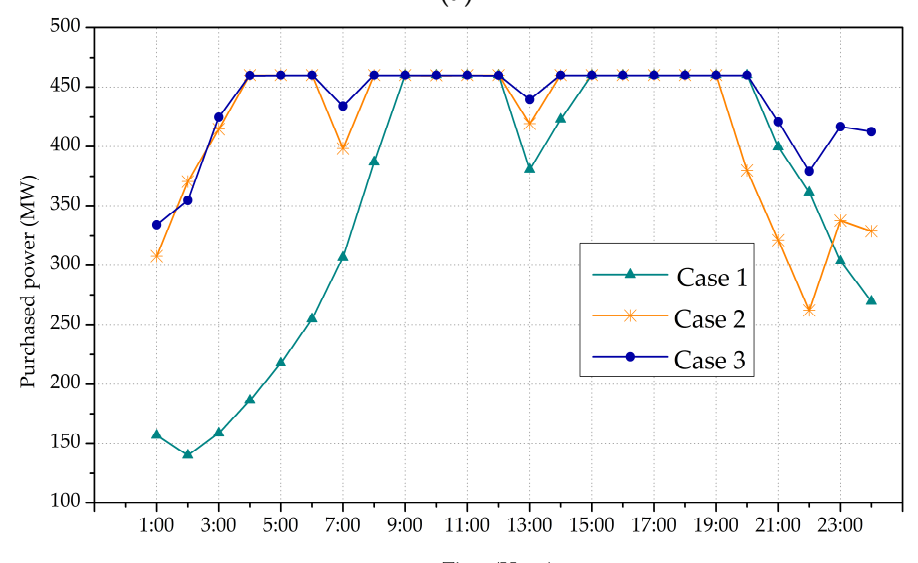

(b)

Figure 6. Cont. 


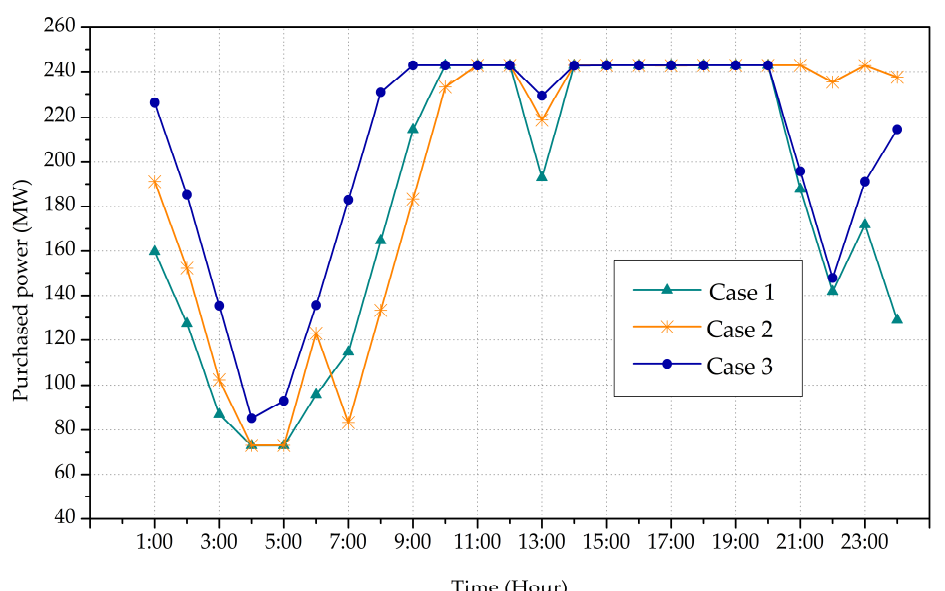

(c)

Figure 6. (a) Purchased power from G1; (b) Purchased power from G2; (c) Purchased power from G3.

The total purchased electricity from each generation company and the unit purchase price are illustrated in Tables 5 and 6.

Table 5. Total purchased electricity.

\begin{tabular}{ccccc}
\hline Case & G1 (MWh) & G2 (MWh) & G3 (MWh) & Overall (MWh) \\
\hline Case 1 & 8227.31 & 8546.24 & 4362.57 & $21,136.12$ \\
Case 2 & 8706.19 & 9980.18 & 4712.30 & $23,398.67$ \\
Case 3 & 9110.95 & $10,516.72$ & 4926.21 & $24,553.88$ \\
\hline
\end{tabular}

Table 6. Unit purchase price.

\begin{tabular}{|c|c|c|c|c|}
\hline Case & G1 (\$/MWh) & G2 (\$/MWh) & G3 (\$/MWh) & Overall (\$/MWh) \\
\hline Case 1 & 29.48 & 29.98 & 29.31 & 29.65 \\
\hline Case 2 & 29.29 & 29.37 & 29.08 & 29.28 \\
\hline Case 3 & 29.16 & 29.19 & 28.96 & 29.13 \\
\hline
\end{tabular}

From Tables 5 and 6, we observe that the retailer purchases more electricity from generation companies after using TOU pricing, especially in Case 3. Meanwhile, the unit purchase price is decreased. This means that the procurement cost is actually reduced by using TOU pricing scheme.

The power purchased from the spot market is shown in Figure 7. As it can be seen, in Case 1, the electricity trade between the retailer and spot market mainly occurs in the daytime. Whereas in Case 2 and Case 3, an obvious change is that the retailer purchases electricity from spot market in the night, meanwhile the purchased power during the daytime is decreased. In Case 2, the amount of electricity purchased from the spot market is decreased by $9.67 \%$. In Case 3, the total purchased electricity from spot market achieves a further reduction from 2324.84 MWh to $2173.48 \mathrm{MWh}$. This can be partially attributed to the reduction of electricity consumption during on-peak hours. Another reason is that the customers shift part of their load to hours with lower prices. Besides, considering the uncertainty in spot prices, purchasing less electricity from spot market theoretically reduces the risk caused by price volatility. 


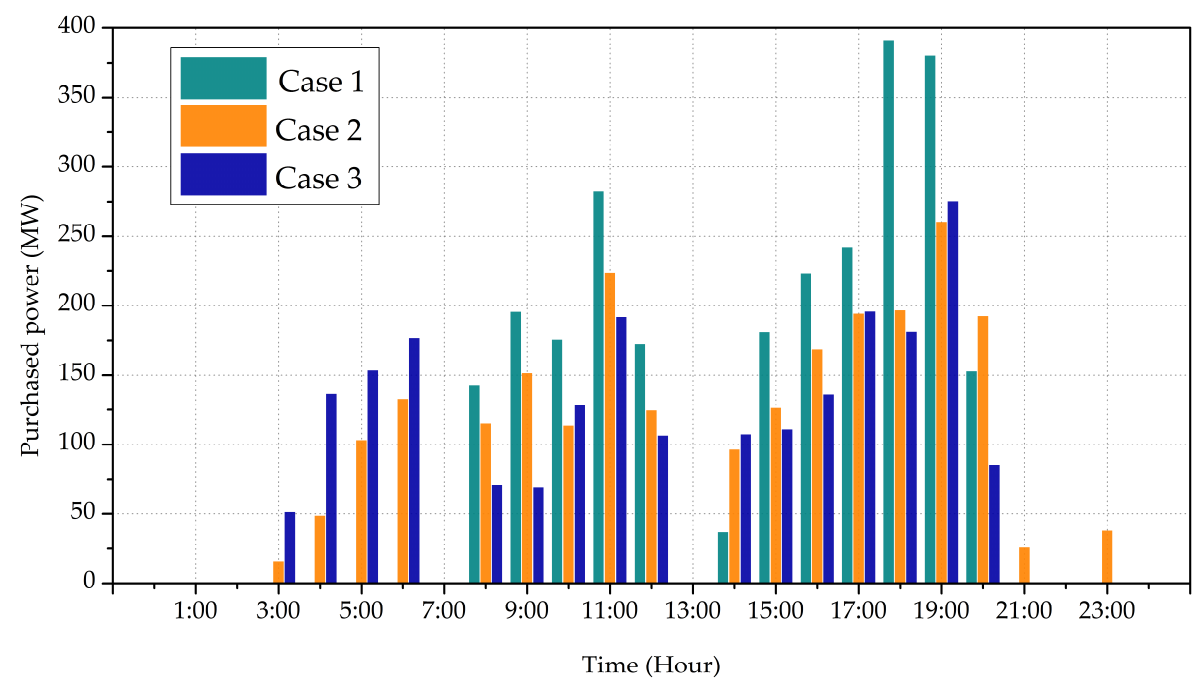

Figure 7. Purchased power from spot market.

The comparison of economic benefit for the retailer is made in Table 7.

Table 7. Comparison of economic benefits.

\begin{tabular}{ccccc}
\hline Case & Revenue (\$) & Cost (\$) & Expect profit (\$) & Unit profit (\$/MWh) \\
\hline Case 1 & $948,392.80$ & $698,102.21$ & $250,290.59$ & 10.56 \\
Case 2 & $1,026,065.01$ & $749,222.06$ & $276,842.95$ & 10.76 \\
Case 3 & $1,066,984.28$ & $774,826.56$ & $292,157.72$ & 10.93 \\
\hline
\end{tabular}

As is shown in Table 7, both the revenue and cost are increased in the second and third cases. As expected, the expected profit of the retailer is significantly increased after applying TOU pricing. More specifically, compared with Case 1, the expected profit in Case 2 is increased by $10.61 \%$ and the corresponding unit profit is increased by $1.89 \%$. Furthermore, on the basis of Case 2, the expected profit in Case 3 is increased by $5.53 \%$ and the corresponding unit profit is increased by $1.58 \%$. The comparison above indicates that the robust model can increase the profit of the retailer through optimizing electricity purchase strategy and electricity selling prices. In the proposed robust model, the retailer uses a robust control parameter $\Gamma_{0}$ to manage economic risks in spot market. Figure 8 presents the change of the spot market cost associated with $\Gamma_{0}$.

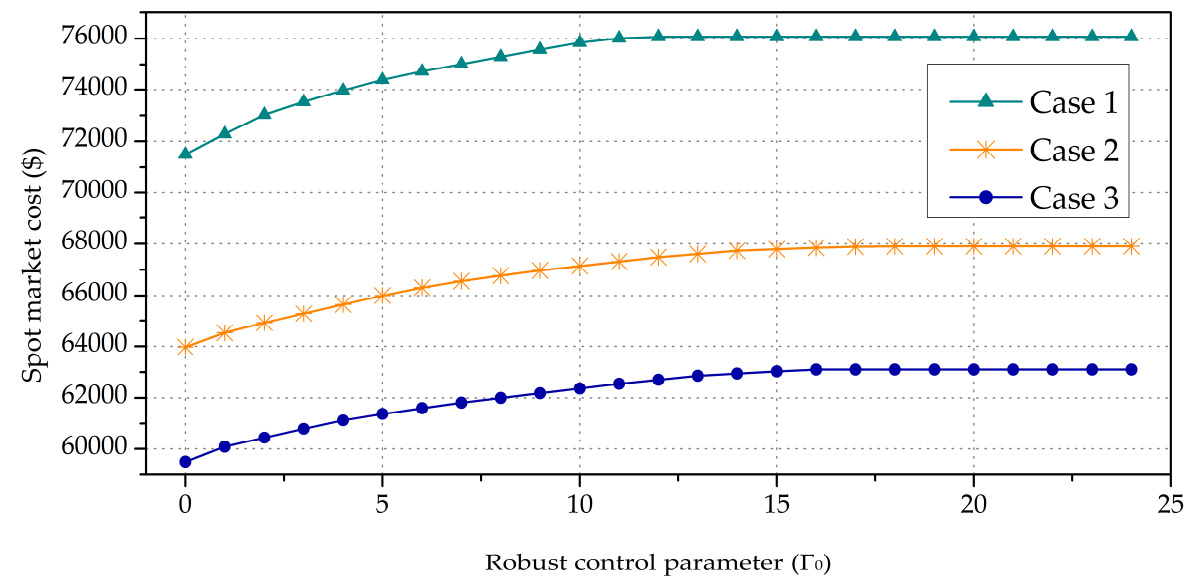

Figure 8. Change of the spot market cost associated with $\Gamma_{0}$. 
As is shown in Figure 8, the spot market cost monotonically increases with the increasing of $\Gamma_{0}$, i.e., the more robust the solution is, the higher the spot market cost is. The increment of the cost can be interpreted as a payment paid by the retailer to hedge against price volatility in spot market. With a higher $\Gamma_{0}$, the retailer can achieve a more robust strategy and reduce the economic risks, and vice versa. This result reflects a tradeoff between benefits and risks. A retailer can choose different values of $\Gamma_{0}$ according to its tolerance to risk, e.g., a risk-averse retailer may choose a higher $\Gamma_{0}$ to avoid risks while a risk neutral retailer may select a relatively lower value to pursue more profit. Another interesting finding is that the spot market cost almost no longer increases when the control parameter $\Gamma_{0}$ reaches a certain integer value. This is mainly because the retailer may purchase only a very small amount of electricity from spot market during some hours. This phenomenon can also be observed in Figure 7.

\section{Conclusions}

In this paper, we propose a robust optimization-based model for the short-term decision- making problem faced by an electricity retailer. The short-term decisions include electricity procurement from generation companies and the spot market, as well as the electricity retail prices. A robust optimization approach is adopted to address the influence of spot price uncertainty on short-term decision making of the retailer. A case study is presented to verify the effectiveness and practicability of the model. Numerical results illustrate that the optimized electricity procurement strategy and TOU pricing scheme can effectively increase the expected profit of the retailer and flatten the load profiles of customers. The generation companies and the power grid will also benefit from the flattened load profiles. Also, the amount of electricity purchased from generation companies is increased while the unit purchase price of electricity is slightly decreased. Besides, the retailer can choose different robust control parameters to control the level of robustness of the solution. In other words, the retailer has ability to achieve a tradeoff between economic benefits and risks according to its risk tolerance. The uncertainty in reference load profiles is not considered in this paper. Uncertainty modeling of other relevant parameters, as well as transmission costs, will be studied in future research.

Author Contributions: Conceptualization, F.H. and X.F.; Data curation, F.H. and X.F.; Formal analysis, X.F.; Investigation, X.F.; Methodology, X.F.; Project administration, F.H.; Resources, F.H.; Software, X.F.; Supervision, H.C.; Validation, H.C.; Writing-original draft, X.F.; Writing-review \& editing, F.H. and H.C.

Funding: This work is supported by National Natural Science Foundation of China (No. 61174154, 2012) and Fundamental Research Fund for the Central Universities (No. xjj2016004, 2016).

Conflicts of Interest: The authors declare no conflict of interest.

\section{Nomenclature}

$\begin{array}{ll}\text { Indices } & \\ t & \text { Index of hours } \\ h & \text { Index of time periods } \\ i & \text { Index of generation companies } \\ j & \text { Index of customers } \\ \text { Sets } & \\ T & \text { Set of hours in a day } \\ H & \text { Set of time periods in a day } \\ T_{j, h} & \text { Set of hours in time period } h \text { for customer } j \\ G & \text { Set of generation companies } \\ C & \text { Set of customers } \\ E_{j} & \text { Price elasticity matrix of customer } j\end{array}$


Parameters and Constants

$a_{i}, b_{i}, c_{i}$

$\underline{\varepsilon_{j}, m, n}$

$\bar{\lambda}_{t}$

$\delta_{t}$

$P_{i}^{\min }, P_{i}^{\max }$

$R U_{i}, R D_{i}$

$P_{j}^{\min }, P_{j}^{\max }$

Variables and Functions

$p_{j, h}$

$q_{j, t}$

$P_{i, t}$

$P_{t}^{s}$

$\lambda_{t}$

$P C$

$S C$

$E R$

$E P$ procurement cost coefficients of generation company $i$

Price elasticity coefficient of customer $j$

Nominal spot price in hour $t$

Maximum possible deviation from nominal spot price in hour $t$

minimum/maximum limit of power generation of generation company $i$

Ramp-up/down limit of power generation of generation company $i$

lower/upper limit of electricity retail price for customers $j$

Electricity retail price for customers $j$ in time period $h$

Electricity demand of customer $j$ in hour $t$

Electricity bought from generation company $i$ in hour $t$

Electricity bought from spot market in hour $t$

Spot price in hour $t$

Procurement cost from generation companies

Spot market cost

Expected revenue

Expected profit

\section{References}

1. Xu, J.; Luh, P.B.; White, F.B.; Ni, E.; Kasiviswanathan, K. Power portfolio optimization in deregulated electricity markets with risk management. IEEE Trans. Power Syst. 2006, 21, 1653-1662. [CrossRef]

2. He, J.; Cai, L.; Cheng, P.; Fan, J. Optimal investment for retail company in electricity market. IEEE Trans. Ind. Inform. 2015, 11, 1210-1219. [CrossRef]

3. Herranz, R.; Munoz San Roque, A.; Villar, J.; Campos, F.A. Optimal demand-side bidding strategies in electricity spot markets. IEEE Trans. Power Syst. 2012, 27, 1204-1213. [CrossRef]

4. García-Bertrand, R. Sale prices setting tool for retailers. IEEE Trans. Smart Grid 2013, 4, 2028-2035. [CrossRef]

5. Gabriel, S.A.; Conejo, A.J.; Plazas, M.A.; Balakrishnan, S. Optimal price and quantity determination for retail electric power contracts. IEEE Trans. Power Syst. 2006, 21, 180-187. [CrossRef]

6. Ugedo, A.; Lobato, E.; Franco, A.; Fernndez-Caro, J.; Chofre, J. Strategic bidding in sequential electricity markets. IEE Proc. Gener. Transm. Distrib. 2006, 153, 431-442. [CrossRef]

7. Baillo, A.; Ventosa, M.; Rivier, M.; Ramos, A. Optimal offering strategies for generation companies operating in electricity spot markets. IEEE Trans. Power Syst. 2004, 19, 745-753. [CrossRef]

8. Carrion, M.; Conejo, A.J.; Arroyo, J.M. Forward contracting and selling price determination for a retailer. IEEE Trans. Power Syst. 2007, 22, 2105-2114. [CrossRef]

9. Carrion, M.; Arroyo, J.M.; Conejo, A.J. A bilevel stochastic programming approach for retailer futures market trading. IEEE Trans. Power Syst. 2009, 24, 1446-1456. [CrossRef]

10. Palamarchuk, S. Dynamic programming approach to the bilateral contract scheduling. IET Gener. Transm. Distrib. 2010, 4, 211-220. [CrossRef]

11. Karandikar, R.G.; Khaparde, S.A.; Kulkarni, S.V. Strategic evaluation of bilateral contract for electricity retailer in restructured power market. Int. J. Electr. Power Energy Syst. 2010, 32, 457-463. [CrossRef]

12. Hatami, A.R.; Seifi, H.; Sheikh-El-Eslami, M.K. Optima selling price and energy procurement strategies for a retailer in an electricity market. Electr. Power Syst. Res. 2009, 79, 246-254. [CrossRef]

13. Kettunen, J.; Salo, A.; Bunn, D.W. Optimization of electricity retailer's contract portfolio subject to risk preferences. IEEE Trans. Power Syst. 2010, 25, 117-128. [CrossRef]

14. Hatami, A.R.; Seifi, H.; Sheikh-El-Eslami, M.K. A stochastic-based decision-making framework for an electricity retailer: Time-of-use pricing and electricity portfolio optimization. IEEE Trans. Power Syst. 2011, 26, 1808-1816. [CrossRef]

15. Charwand, M.; Ahmadi, A.; Heidari, A.R.; Esmaeel Nezhad, A. Benders decomposition and normal boundary intersection method for multiobjective decision making framework for an electricity retailer in energy markets. IEEE Syst. J. 2015, 9, 1475-1484. [CrossRef]

16. Zakariazadeh, A.; Jadid, S.; Siano, P. Smart microgrid energy and reserve scheduling with demand response using stochastic optimization. Int. J. Electr. Power Energy Syst. 2014, 63, 523-533. [CrossRef] 
17. Hosseini Imani, M.; Zalzar, S.; Mosavi, A.; Shamshirband, S. Strategic Behavior of Retailers for Risk Reduction and Profit Increment via Distributed Generators and Demand Response Programs. Energies 2018, 11, 1602. [CrossRef]

18. Siano, P. Demand response and smart grids-A survey. Renew. Sustain. Energy Rev. 2014, 30, 461-478. [CrossRef]

19. Yu, M.; Hong, S.H. A real-time demand-response algorithm for smart grids: A stackelberg game approach. IEEE Trans. Smart Grid 2016, 7, 879-888. [CrossRef]

20. Yang, P.; Tang, G.; Nehorai, A. A game-theoretic approach for optimal time-of-use electricity pricing. IEEE Trans. Power Syst. 2013, 28, 884-892. [CrossRef]

21. Jia, L.; Tong, L. Dynamic pricing and distributed energy management for demand response. IEEE Trans. Smart Grid 2016, 7, 1128-1136. [CrossRef]

22. Kirschen, D.S. Demand-side view of electricity market. IEEE Trans. Power Syst. 2003, 18, 520-527. [CrossRef]

23. Su, C.L.; Kirschen, D. Quantifying the effect of demand response on electricity markets. IEEE Trans. Power Syst. 2009, 24, 1199-1207. [CrossRef]

24. Ferreira, R.S.; Barroso, L.A.; Lino, P.R.; Carvalho, M.M.; Valenzuela, P. Time-of-use tariff design under uncertainty in price-elasticities of electricity demand: A stochastic optimization approach. IEEE Trans. Smart Grid 2013, 4, 2285-2295. [CrossRef]

25. Celebi, E.; Fuller, J.D. A model for efficient consumer pricing schemes in electricity markets. IEEE Trans. Power Syst. 2007, 22, 60-67. [CrossRef]

26. Horowitza, I.; Woo, C.K. Designing pareto-superior demand-response rate options. Energy J. 2006, 31, 1040-1051. [CrossRef]

27. Aalami, H.A.; Parsa Moghaddam, M.; Yousefi, G.R. Modelling and prioritizing demand response programs in power markets. Electr. Power Syst. Res. 2010, 80, 426-435. [CrossRef]

28. Kim, H.; Shcherbakova, A. Common failures of demand response. Energy J. 2011, 36, 873-880. [CrossRef]

29. Celebi, E.; Fuller, J.D. Time-of-use pricing in electricity markets under different market structures. IEEE Trans. Power Syst. 2012, 27, 1170-1181. [CrossRef]

30. Weron, R. Electricity price forecasting: A review of the state-of-the-art with a look into the future. Int. J. Forecast. 2014, 30, 1030-1081. [CrossRef]

31. Soroudi, A. Robust optimization based self scheduling of hydro-thermal Genco in smart grids. Energy 2013, 61, 262-271. [CrossRef]

32. Cincotti, S.; Gallo, G.; Ponta, L.; Raberto, M. Modeling and forecasting of electricity spot-prices: Computational intelligence vs. classical econometrics. AI Commun. 2014, 27, 301-314. [CrossRef]

33. Shabanzadeh, M.; Sheikh-El-Eslami, M.K.; Haghifam, M.R. The design of a risk-hedging tool for virtual power plants via robust optimization approach. Appl. Energy 2015, 155, 766-777. [CrossRef]

34. Soyster, A.L. Convex programming with set-inclusive constraints and applications to inexact linear programming. Oper. Res 1973, 21, 1019-1175. [CrossRef]

35. Fotouhi Ghazvini, M.A.; Soares, J.; Morais, H.; Castro, R.; Vale, Z. Dynamic Pricing for Demand Response Considering Market Price Uncertainty. Energies 2017, 10, 1245. [CrossRef]

36. Kirschen, D.S.; Strbac, G.; Cumperayot, P.; de Paiva Mendes, D. Factoring the elasticity of demand in electricity prices. IEEE Trans. Power Syst. 2000, 15, 612-617. [CrossRef]

37. Zhao, C.; Wang, J.; Watson, J.P.; Guan, Y. Multi-stage robust unit commitment considering wind and demand response uncertainties. IEEE Trans. Power Syst. 2013, 28, 2708-2717. [CrossRef]

38. Safdarian, A.; Fotuhi-Firuzabad, M.; Lehtonen, M. A medium-term decision model for DisCos: Forward contracting and TOU pricing. IEEE Trans. Power Syst. 2015, 30, 1143-1154. [CrossRef]

39. Wang, J.; Kennedy, S.W.; Kirtley, J.L. Optimization of forward electricity markets considering wind generation and demand response. IEEE Trans. Smart Grid 2014, 5, 1254-1261. [CrossRef]

40. Ponta, L.; Roberto, M.; Teglio, A.; Cincotti, S. An Agent-based Stock-flow Consistent Model of the Sustainable Transition in the Energy Sector. Ecol. Econ. 2018, 145, 274-300. [CrossRef]

41. Nojavan, S.; Mohammadi-Ivatloo, B.; Zare, K. Robust optimization based price-taker retailer bidding strategy under pool market price uncertainty. Int. J. Electr. Power Energy Syst. 2015, 73, 955-963. [CrossRef]

42. Bertsimas, D.; Sim, M. Robust discrete optimization and network flows. Math. Program. 2003, 98, 49-71. [CrossRef] 
43. Zhang, H.; Zhao, F.; Fang, K.; Sutherland, J.W. Energy-conscious flow shop scheduling under time-of-use electricity tariffs. CIRP Ann. Manuf. Technol. 2014, 63, 37-40. [CrossRef]

44. Liu, G.; Xu, Y.; Tomsovic, K. Bidding strategy for microgrid in day-ahead market based on hybrid stochastic/robust optimization. IEEE Trans. Smart Grid 2016, 7, 227-237. [CrossRef]

45. Baringo, L.; Conejo, A.J. Offering strategy via robust optimization. IEEE Trans. Power Syst. 2011, 26, 1418-1425. [CrossRef] 